\title{
The Application of New Techniques in Landscape Engineering
}

\author{
Shuisheng Lu ${ }^{1,}$ a \\ ${ }^{1}$ Nanchang Institute of Science and Technology, 330108, Nanchang, China \\ a19924298@qq.com
}

Keywords: techniques, technology, landscape engineering, application

\begin{abstract}
To realize the urban afforestation construction, it weights a lot to highlight the landscape construction and build the Eco-City. The emergency of new techniques has brought new progress into Chinese afforestation construction and shaped a unique landscape construction technology whose combination with landscape technology has realized an innovation on it. This innovation performs a key role in the landscape modernization construction. In this paper, basing on the traditional garden engineering techniques, the author has conducted a thorough research fro the importance of new techniques to the related issues such as realization and the associated opinions of them putting in the garden engineering.
\end{abstract}

\section{Introduction}

Bestowed by the rich culture and unique garden construction style, China has won a great fame in the afforestation field. The traditional landscape pays more attention on the harmony between man and nature, which has fully expressed the effective integration between living surrounding and nature. In recent years, garden construction has gained various kinds of construction laws and aesthetic theories in varied areas biding with high-speed urban construction, thus leading to different afforestation techniques. The most eye-catching result is the perfect match between the traditional and the new technique, which adds more features on the modern constructions and pushes the landscape techniques to move forward faster. Given this background, the practical use of new techniques in garden projects becomes the pending issue here.

\section{Traditional Landscape Technology}

There exists a long and rich history in Chinese landscape afforestation construction. The most famous one is the Suzhou Garden, which represents China's afforestation skills and technology in a degree. Take this traditional garden as an example, pavilions, rockeries and brooks in it have made this place alive in the middle of city by integrating the living surrounding and nature together. To put it more specific and detailed, there are some features of Chinese traditional garden constructions.

(1) A frame of mountains and water

The most common elements of Chinese traditional gardens we can see are rockeries and water. For one reason, these two elements are moving and vigorous which contributes the sense of life into it. For the other, rockery and water are regarded as the Yin and Yang deficiency in Chinese geomantic theory. Thus highlight the rock and water out in the landscape construction is appropriate according to the traditions, which makes the garden a delight to watch. Above all, the typical geographical condition and cultural background of China has imposed great influence on its landscape afforestation construction and technology.

(2) Poetic and pictorial landscape

If there allows only one expression to describe Chinese traditional constructions, "poetic and pictorial scenery' is the best choice. The designers in the past were influenced by philosophy and painting aesthetic thoughts and employed two techniques of borrowing the scenery from the distance and feeling and setting happily blended. This tradition has shown not only the basic 
afforestation principle, also the harmony between man and nature, which enables the 'painting-in-poetry' blending into the landscape construction. This makes the traditional architects stands different from the modern ones.

(3) Adjustments to local conditions and landscapes

Almost every Chinese traditional garden technique fully expresses the adjustment to local conditions and landscapes. This is the very first principle to obey and analyze associated elements. Then there comes out the topic and specific arrangements in the garden by borrowing views and enframed scenery ways to reasonably collocate the layout. Finally, the designers deliberated the specific arrange in the garden to make sure it's the same with the original afforestation goal.

\section{The Application of New Techniques}

Chinese traditional landscape afforestation construction has contributed a lot for the modern development to a great extent. Still, in the final analysis all gardens of either traditional or modern are the results of people changing and inventing new environments. All discussion comes to the gardens' functionality. The traditional ones are more private hold estates while modern gardens are made for the common space. With the employment of traditional techniques in the modern design, there realizes a development in the modern landscape construction. Things change rather fast in recent years with modern scientific technologies emerging, which have shown an influential effect in the modern progress.

(1) Satisfaction for the urban modernization development

There is an increasing contradiction on the balance between economy growth and environment protection in years. The living environment has been destroyed badly and been challenged to some extent. Under this circumstance, people are paying more and more attention on the environment protection, putting forward the eco-city idea and coming up some more requires for the modern garden construction. Basing on the features of modern city, traditional landscape techniques solely cannot meet the requirement of modern gardens. A combination with new techniques is applicable in this modern landscape construction to make them a delight to watch on one side and produce more economic and ecological effect on the other side.

(2) Further optimization for traditional garden techniques

The practical use of new technologies has realized an optimization on the traditional ways in building a garden. There are many high-tech techniques being implemented in the modern garden construction. For example, FRP and GRC are appeared as the new material for the traditional rockery stones. They meet both goals to save nature resource and work out the same delight for people with the traditional ones. In overall, the most outstanding outcome of new techniques into the landscape construction is the optimization of the past.

\section{A Case Study of New Techniques Practical Use}

Landscape engineering has experienced a long history and now the modern landscape engineering has embodied with rich meanings and functions of trees and greens, rocks and water and architecture together. Thus is called as comprehensive urban landscape engineering. Till now, the emergence and employment of new techniques in landscape engineering has realized not only the perfectness of traditional garden engineering construction, but also the economic and ecological beneficial results. For example, FRP and GRC are the replace rockery materials for landscape engineering and other large-scale engineering projects. There is a real situation happened in a Tiaozini inning project in Yancheng City of Jiangsu Province. One of the tricky problems is the rusting and corruption of the reinforcement in the sea splash zone. The salt, magnesium and sulfate in the sea would badly damage the steel durability finally result in reinforcement get rusted and weak project quality. Through a series of theory analysis and practice, they used FRP replace the reinforced concrete slabs solving the problem and postponed the project duration. There is another case happened in Zhijiang Garden of employing FRP and GRC to reach a better performance. 
To conclude from these cases above, new techniques are getting a full employment in actual projects and work as an important part in both landscape engineering development and high quality.

\section{Application of New Techniques in Landscape Engineering}

Basing on the bedding of traditional garden engineering technology and the importance if new techniques, it's better to reasonably employ the new techniques in garden construction for a green and ecological city. It also means a lot in improving the garden engineering quality. Besides, there raises some more requirements for the actual employment of new techniques in landscape engineering. Take the new rockery materials FRP and GRC as an example, a comprehensive consideration is important in actual practice. Therefore, it is quite important for the landscape engineering development to proficiently master the new techniques.

(1) Scientific resource collocation

The practice of new techniques should make sure to reach the expectation. First, there needs an optimization for the existing resources to allow the resources play to their full usage. Second, some associated building skills are required to cope with the actual landscape conditions and needs and realize an optimization of the landscape engineering. To put it simply, the actual practice should strictly adhere to the principle of 'adjustment to the local conditions' and effectively distribute the resources for the best ecological benefit, which is the final and last goal of landscape engineering projects.

(2) Further development of New Techniques

For the actual use of new techniques, the most important thing is to have a long vision of its future. Chinese gardens are all equipped with long histories by which produced lots of unique gardens like Suzhou Garden. Their skills are used till now. While with different and new background, the living society changes over time and the garden projects are the outcome of both living environment and nature. This fact has made us to conceive things in the long run to keep us along with the new techniques development and to be on a sustainable development of landscape engineering.

(3) Upgrading of garden design

People are now holding a high taste for fancy horticultural projects with a growing material life quality asking for a delight in viewing and more meanings in further study. For that, there requires more on the design optimization of the garden. Given different time and place, there exist different needs and varied kinds of optimization plans for the garden engineering. Sticking to the "unity of man and nature' principle and realizing the integration of living life and nature can promote the landscape engineering development.

(4) Imitation of natural landscape

With the rapid development of modern technologies, they have played their positive roles and realized an imitation of natural landscape, which cannot be staged before. It not only raises the appreciation of landscape projects, but also increases their economic benefits. This natural landscape imitation bases the general building structure, combines with manual techniques to build the framework and better realizes a harmony relationship between human and nature. Taking the Golden River Garden in Shandong Yantai City (such as Fig 1) for an example, there is an artificial river way by imitating the nature. In the garden scheme, the Golden River is tapped as the best landscape and the most important ecological corridor in the Development Zone. Natural landscape imitation method has been widely employed in garden project especially in the first design stage. This method helps to build a more third-dimensional and spatial dimensional garden blueprint so as to timely adjust the design and apply into the landscape construction process, which forms a great assistant in the landscape design and real construction. 


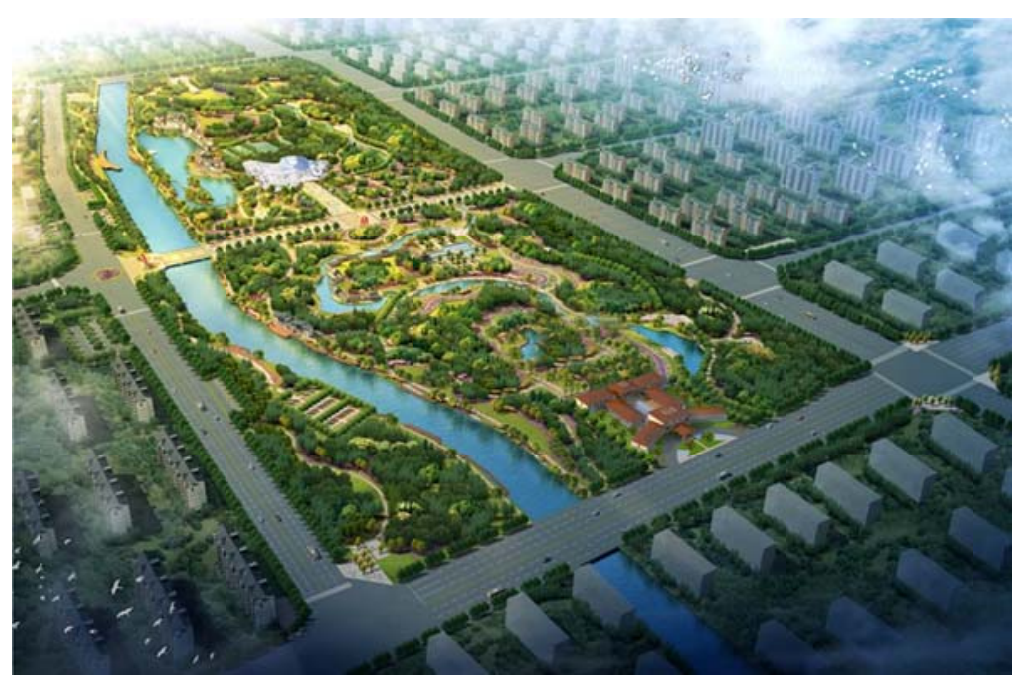

Fig 1 natural landscape simulation figure

\section{Conclusion}

From all the discussions above, new techniques means a lot in the actual landscape engineering. Various skills have satisfied both the optimization and quality of garden engineering, by which garden engineering has produced great ecological and economic benefits. There is no denying that the need for landscape engineering is not a need from just one time, but changes over time. This reminds us to perceive it as a long-run matter and keep upgrading its skills.

\section{References}

[1] Peihong Yang, Xiaolei Jiang. Research on Landscape Engineering Vegetation Construction Organization Management-Take First-line Vegetation Construction Management in Yellow River Senic Area as Example [J]. Journal of Anhui Agricultural Sciences, 2010, 38 (13): 7098-7100.

[2] Haiming Fan, Shengbin Luo, Dejun Zhou. A Life Vision on Community Garden Engineering - How to Build a Community Garden Engineering of Reasonable Soul [J]. Real Estate Biweekby, 2015,(35):238.

[3] Meirong Lin, Xuerong Lin. An Analysis on Responsibility Cost Management in a Developing Landscape Engineering-Take China Tietong Fenglingshanyucheng Garden Engineering as Example [J]. Chinese Horticulture Abstract, 2014, (8): 63-64,132.

[4] Hui Tang, Yun Lin, Xiaoshan Cheng. Landscape Engineering Teaching Transformation and Innovation under the Principle of 'the Unity of Technology and Knowledge'-Take the Landscape Architect Major in South China Agricultural University as Example [J]. Chinese Forrest Education, 2016,34(6):50-54.

[5] Yunfeng Jin, Yi Du, Guang Chen. A Review of Ecological Engineering-Basing on the Second Discipline of Landscape Architect Engineering Aspect [J]. Chinese landscape Architect, 2015,31(2):89-93.

[6] Feng Ni. New Techniques Application of Landscape Construction and the Management Methods [J]. Modern Horticulture, 2016, (6): 192-192.

[7] Xiangpin Zhou, Yuanyuan Liu. Transformation and Integeration-Development of Wuhan Modern Landscape and Enlightens for Now [J]. Urban Planning Forum, 2010,(2): 111-119.

[8] Yuli Tang, Haiyan Qianm Wei Zhu. Poetic and Pictorial Landscape in Xihu Cultural Landscape-A Thoughtful Discussion of Hangzhou Garden Design on The $10^{\text {th }}$ China (Wuhan) International Garden Expo [J]. Chinese Landscape Architecture, 2017,33(2):61-65. 